\title{
Quantitative Angiographic Follow-Up of the Coronary Wallstent in Native Vessels and Bypass Grafts (European Experience - March 1986 to March 1990)
}

\author{
Bradley H. Strauss, MD, * Patrick W. Serruys, MD, PhD, Michel E. Bertrand, MD, \\ Jacques Puel, MD, Bernhard Meier, MD, Jean-Jacques Goy, MD, Lukas Kappenberger, MD, \\ Anthony F. Rickards, MD, and Ulrich Sigwart, MD, with the technical assistance of \\ Marie-Angèle Morel and Eline Montauban van Swijndregt
}

The coronary stent has been investigated as an adjunct to percutaneous transluminal coronary angioplasty to obviate the problems of early occlusion and late restenosis. From March 1986 to March 1990, 265 patients (308 lesions) were implanted with the coronary Wallstent in 6 European centers. For this study, the patients were anaIyzed according to date of implantation (group 1, March 1986 to January 1988; group 2, February 1988 to March 1990) and vessel type (native arteries versus bypass grafts). Quantitative angiographic follow-up was performed in $82 \%$ of the study patients. The early in-hospital occlusion rate in the overall group was 15\%. Group 1 patients had a $20 \%$ rate in contrast to $12 \%$ rate in group 2 ( $p=$ not significant [NS]). The early occlusion rate in native vessels and bypass grafts was 19 and $8 \%$, respectively ( $p=0.019)$. Restenosis was determined by 2 criteria (criterion $1, \geq 0.72 \mathrm{~mm}$ loss in minimal luminal diameter from poststent to follow-up; criterion 2, $\geq 50 \%$ diameter stenosis at follow-up) within the stent and in the segments immediately proximal and distal to the stent. The restenosis rate with criterion 1 was $43 \%$ in the overall group of patients, $35 \%$ in group 1 versus $49 \%$ in group 2 ( $p=N S$ ), and $34 \%$ in native vessels versus $54 \%$ in bypass grafts $(p=0.016)$. The second criterion was met by $27 \%$ of patients in the over-

From the Catheterization Laboratory, Thoraxcenter, Rotterdam, the Netherlands; Department of Cardiology, Hôpital Cardiologique, Lille, France; Department of Clinical and Experimental Cardiology, Centre Hospitalier Regional Universitaire, Rangueil, Toulouse, France; Cardiology Center, University Hospital, Geneva, Switzerland; Division of Cardiology, Department of Medicine, Centre Hospitalier Universitaire Vaudois, Lausanne, Switzerland; and Department of Invasive Cardiology, The Royal Brompton and National Heart Hospital, London, United Kingdom. Dr. Strauss is the recipient of a Research Fellowship from the Heart and Stroke Foundation of Canada. This study was supported in part by Grant 87159 from the Dutch Ministry of Science and Education, Den Haag, the Netherlands and Grant 3,835,083 from the Swiss National Fund. Manuscript received July 24, 1991; revised manuscript received and accepted October 25, 1991

*Current address: Bradley H. Strauss, MD, St. Michael's Hospital Division of Cardiology, 30 Bond Street, Toronto, Ontario, Canada M5B 1W8.

Address for reprints: Patrick W. Serruys, MD, Catheterization Laboratory, Thoraxcenter, Erasmus University, P.O. Box 1738, 3000 DR Rotterdam, the Netherlands. all group, $21 \%$ in group 1 versus 32\% in group 2 $(p=N S)$, and $18 \%$ in native vessel versus $39 \%$ in bypass grafis $(p=0.005)$. The overall mortallty during the study period was $\mathbf{6 . 6 \%}$ in native arteries and $9 \%$ in bypass grafts ( 6 and $7.9 \%$ at 1 year, respectively). The actuarial event-free survival (freedom from death, myocardial infarction, bypass surgery or angloplasty) for native artery patients was $\mathbf{4 6 \%}$ at $\mathbf{4 0}$ months and for bypass graft patients $\mathbf{3 7 \%}$ at $\mathbf{2 0}$ months.

It is concluded that early in-hospital occlusions remain a major problem with this device despite improvement in the later experience. Although patients with bypass grafts had a significantly lower early occlusion rate than those with implantation of native arteries, a significantly higher rate of late restenosis limited the early benefits of stenting. The indications for stenting remain unknown and require results of randomized clinical studies.

(Am J Cardiol 1992,69:475-481)

$\mathrm{I}$ n 1986, the first coronary Wallstent ${ }^{\mathrm{TM}}$ implantation ushered in a new era in interventional cardiology with the purpose of circumventing the 2 major limitations of coronary angioplasty, early acute occlusion and late restenosis. ${ }^{1} \Lambda s$ with all new procedures, operators of the device had to struggle with their own learning curves at the same time that anticoagulation regimens and clinical indications and contraindications evolved from their clinical experience. In May 1988, the 5 European centers testing this device agreed to set up a core laboratory for quantitative angiographic analysis in Rotterdam to assess the results objectively. In a previous publication from our group, the late angiographic and clinical follow-up of the initial 105 patients was reported. ${ }^{2}$ These stent implantations were predominantly performed in native coronary vessels. In the period from February 1988 until March 1990, an additional 160 patients underwent stent implantation in the coronary circulation. This second group was characterized by a predominance of bypass vessels and a different set of indications. In this report, we compared the late quantitative angiographic and clinical follow-up of this second group of patients with the initial group, and assessed bypass grafts versus native vessels. In particular, we 


\begin{tabular}{|c|c|c|}
\hline & $\begin{array}{c}\text { Group 1 } \\
\text { (March 1986- } \\
\text { January 1988) }\end{array}$ & $\begin{array}{c}\text { Group } 2 \\
\text { (February 1988- } \\
\text { March 1990) }\end{array}$ \\
\hline Vessels & 107 & 175 \\
\hline Stents/narrowings & $117 / 114$ & $266 / 194$ \\
\hline \multicolumn{3}{|l|}{ Site of narrowings } \\
\hline Bypass conduits & $29(18 \%)$ & $116(60 \%)$ \\
\hline Native vessels & $94(82 \%)$ & $78(40 \%)$ \\
\hline LAD & $62(54 \%)$ & $29(15 \%)$ \\
\hline LC & $8(7 \%)$ & $10(5 \%)$ \\
\hline Right & $24(21 \%)$ & $39(20 \%)$ \\
\hline
\end{tabular}

were interested in determining whether the changing patterns of patient selection and management based on the initial experience resulted in improved rates of early occlusion and late restenosis and whether the results of stents implanted in bypass grafts differed from native vessels.

\section{METHODS}

Study patients: Two hundred sixty-five patients (308 narrowings) were enrolled after obtaining informed consent between March 1986 and March 1990 at the participating centers. The study protocol was approved by the individual hospital ethics committees. The mean age of the population was $58 \pm 11$ years and $84 \%$ were men. The study patients were grouped according to the date of implantation (March 1986 to January 1988, February 1988 to March 1990, groups 1 and 2, respectively) and the vessel type (native vessel versus bypass graft) (Table I). The first period of stent implantations, until January 1988, has previously been reported. ${ }^{2}$ Almost $90 \%$ of the first group underwent implantation at either Lausanne $(n=56)$ or Toulouse $(n=32)$. However, in the second period, about $80 \%$ of the patients underwent implantation in Rotterdam $(n=80)$ and in Lausanne ( $n=43$ ). In Group 1, 117 stents were implanted in 114 narrowings, of which $82 \%$ were in native vessels (in particular the left anterior descending artery). In group 2, 266 stents were implanted in 194 narrowings, predominantly in bypass grafts. In this group, the right coronary artery was the most common vessel implanted in the native circulation. Two patients had stents placed in both a bypass graft and a native vessel. The indications for stenting also differed between the 2 vessel types (Figure 1). Native vessels were pri- marily stented to prevent a second restenosis or as a bail-out procedure for angioplasties complicated by abrupt closure or large dissections that interrupted anterograde flow and were associated with clinical and electrocardiographic signs of ischemia. However, in bypass grafts, the principle indication was for primary lesions that had not been previously treated with angioplasty.

In this trial, the endovascular prosthesis, Wallstent ${ }^{\star}$, was provided by Schneider Europe, Zurich. The method of implantation and description of this stent has previously been reported. ${ }^{1-5}$ Unconstrained stent diameter ranged from 2.5 to $6 \mathrm{~mm}$ and was selected to be 0.50 $\mathrm{mm}$ larger than the stented vessel. In an effort to alleviate the problem of acute thrombosis, the stent design was changed in April 1989 with the introduction of a polymer-coated stent (Biogold ${ }^{\star}$ ) for some stent sizes. By August 1989, all manufactured stents contained this particular polymer coating.

The anticoagulation for the first period of implantation has previously been described. ${ }^{2}$ Based on this initial clinical experience, a uniform anticoagulation schedule was followed at the centers. Therapy with acetylsalicylic acid, $1 \mathrm{~g}$ orally, was begun 1 day before the procedure. At the beginning of the procedure, patients received heparin, 10,000 IU intravenously, and in some cases, dextran infusions $(500 \mathrm{mg} / 4$ hours) were also given. Heparin (10,000 IU) and urokinase (100,000 U) were administered by intracoronary infusion during the procedure. After the procedure, the heparin infusion was adjusted according to the activated partial thromboplastin time (desired range 80 to 120 seconds) in addition to initiating oral vitamin $\mathrm{K}$ antagonist therapy. Heparin was discontinued after the therapeutic oral anticoagulation level was stabilized (international normalized ratio $>2.3)$. Acetylsalicylic acid $(100 \mathrm{mg} /$ day $)$, dipyridamole ( 300 to $450 \mathrm{mg} /$ day), and in some patients sulfinpyrazone $(400 \mathrm{mg} /$ day $)$ were also administered.

Quantitative coronary arteriography and restenosis criteria: All cineangiograms were analyzed at the core laboratory in Rotterdam using the computer-assisted cardiovascular angiography analysis system which has previously been discussed in detail.6,7 The minimal luminal diameter and percent diameter stenosis were determined before and after angioplasty, immediately after stent implantation and at long-term follow-up in all patients using the average of multiple matched views with orthogonal projections wherever possible. The min-

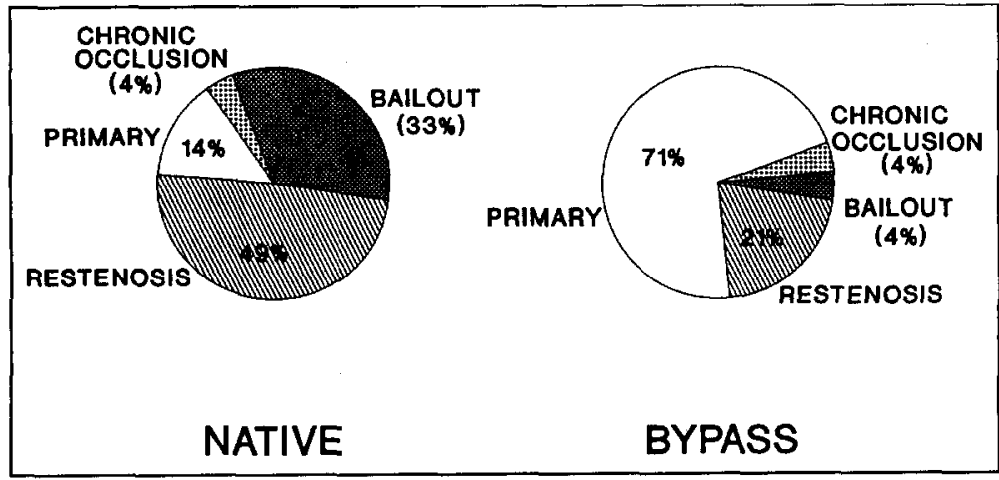

FGURE 1. The indications for stenting in native arteries and bypass grafts. Primary = primary atherosclerolic lesion that has not been previously treated by angioplasty or stenting. 
imal luminal diameter (and the diameter stenosis using the reference diameter of the segment) of each segment immediately proximal and distal to the stent was also measured.

Two different sets of criteria were applied to determine the restenosis rate. We have found a change in minimal luminal diameter of $\geq 0.72 \mathrm{~mm}$ (criterion 1) to be a reliable indicator of angiographic progression of vessel narrowing and by no means implies functional or clinical significance. $3,4,8$ This value takes into account the limitations of coronary angiographic measurements and represents 2 times the long-term variability (i.e., the 95\% confidence intervals) for repeat measurements of a coronary obstruction using our system. Criterion 2 for restenosis was an increase of the diameter stenosis from $<50 \%$ after stent implantation to $\geq 50 \%$ at follow-up. This criterion was selected since common clinical practice continues to assess lesion severity by a percent stenosis. The 2 criteria were assessed within and in the segment immediately adjacent (proximal and distal) to the stent.

In this study, late (i.e., documented after the initial discharge from hospital) occlusion ( $\mathrm{n}=10$ patients, 16 lesions) was regarded as restenosis. This contrasts with our earlier report in which we calculated a total occlusion rate that was then separated into early (in hospital) and late occlusions. ${ }^{2}$ In that report, the early and late occlusions were analyzed separately from the restenotic lesions. The current change was initiated to be consistent with our reports of late follow-up of angioplasty. 4,9

Statistical methods: The data obtained by quantitative angiographic analysis are given as mean \pm standard error of the mean. The means for each angiographic variable before angioplasty, after stent and at follow-up were compared by analysis of variance. If significant differences were found, 2-tailed $t$ tests were applied to pairs of data. The occlusion and restenosis rates were compared using a chi-square test. A statistical probability $<0.05$ was considered significant.

The late clinical follow-up was determined according to a life-table format using the Kaplan-Meier method. ${ }^{10}$ The following events were considered clinical end points: death, myocardial infarction, bypass surgery or nonsurgical revascularization (angioplasty or atherectomy). The life table was constructed according to the initial clinical event.

\section{RESULTS}

The angiographic follow-up for the entire study population was $82 \%$ (Table II). This includes patients with documented early occlusions during hospital admission $(n=40)$ in addition to patients who had late (after the initial hospital discharge) angiography. The reasons why follow-up angiography could not be performed are listed in Table II. The time to angiographic follow-up was $6.6 \pm 4.8$ months if early occlusions are excluded and $5.7 \pm 5.0$ months with the early occlusions.

The angiographic data for individual lesions in bypass grafts and native vessels are presented in Figures 2 and 3 . In native vessels, there was a mean increase in minimal luminal diameter $(\mathrm{mm})$ from $1.17 \pm 0.04$ to $2.53 \pm 0.04$ immediately after stenting $(p<0.0001)$, but a late deterioration to $1.99 \pm 0.07$ ( $p<0.0001$ versus the poststent result) if early occlusions are excluded and $1.59 \pm 0.09$ with the inclusion of the early $\alpha$ clusions ( $p<0.0001)$. Similarly, the minimal luminal diameter increased significantly in bypass narrowings from $1.39 \pm 0.06$ to $2.81 \pm 0.06$ after stenting with a late reduction to $2.21 \pm 0.11$ and $2.03 \pm 0.12$ with the exclusion and inclusion of early occlusions, respectively ( $p<0.0001)$. Diameter stenosis was significantly re-

\begin{tabular}{|ccc|}
\hline TABLE U Angiographic Follow-Up & \\
\hline Implantations (lesions/patients) & $308 / 265$ & \\
Early occlusions & $41 / 40$ & \\
Late follow-up & $214 / 176$ & \\
Total & $255 / 216$ & $(82 \%)$ \\
No angiographic follow-up & $53 / 49$ & $(18 \%)$ \\
Death & 10 & $(4 \%)$ \\
Early bypass surgery & 11 & $(4 \%)$ \\
Refusal & 25 & $(9 \%)$ \\
Technical & 3 & $(1 \%)$ \\
Time to angiographic follow-up & & \\
Excluding early occlusions & $6.6 \pm 4.8$ & \\
Including early occlusions & $5.7 \pm 5.0$ & \\
\hline
\end{tabular}
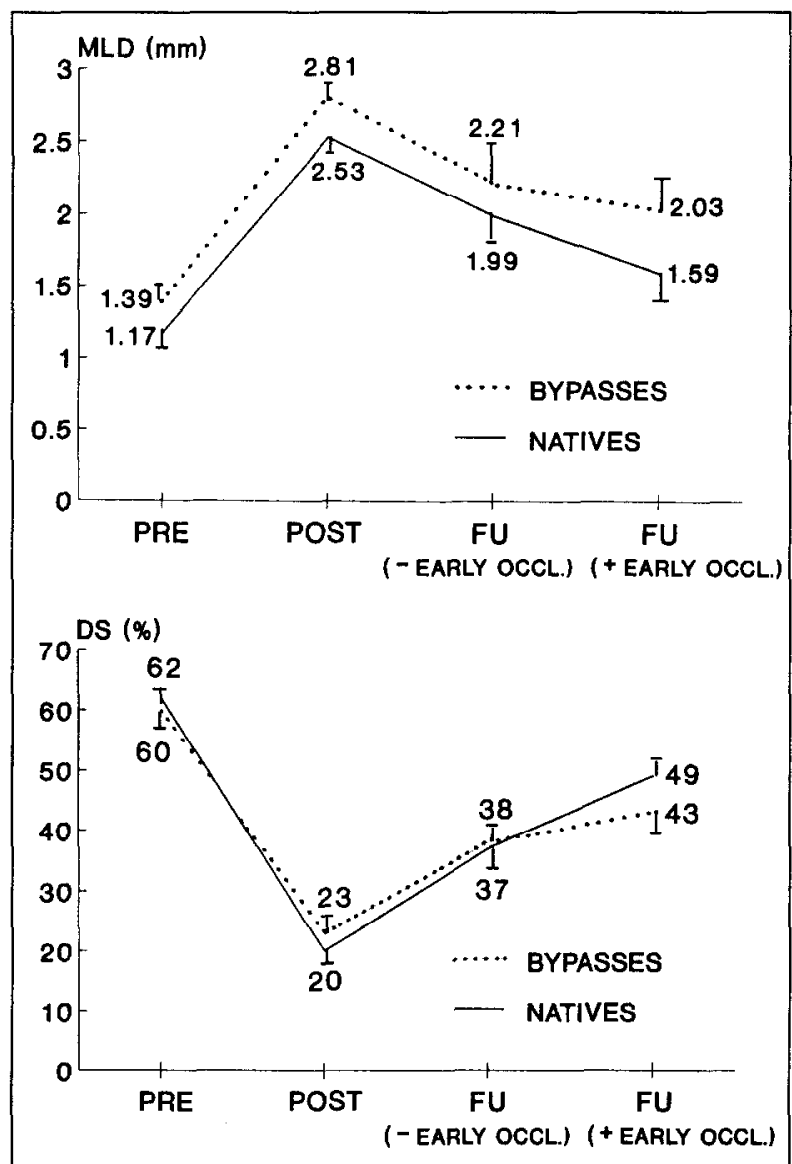

FIGURE 2. Top, minimal huminal diamoter (MLD) of native vessels and bypass grafts before (PRE) procedure, after (POST) stenthis, and at followtu (FU). Mean values at followup have been ealeulated with and without the melueion of the earty in hoepitsl ocelucions (OCCL.). DS = diemeter stenosts. Boftom, percent dimmeter stenodis (DS) of nattve vesecks and bypass grafts belore precedure, affer stenting, and at followup. Moen values at follow-tp have been calculated with and without the incluaton of the earty in-hospital cectusions. MLD = minimal buninal dilameter. 


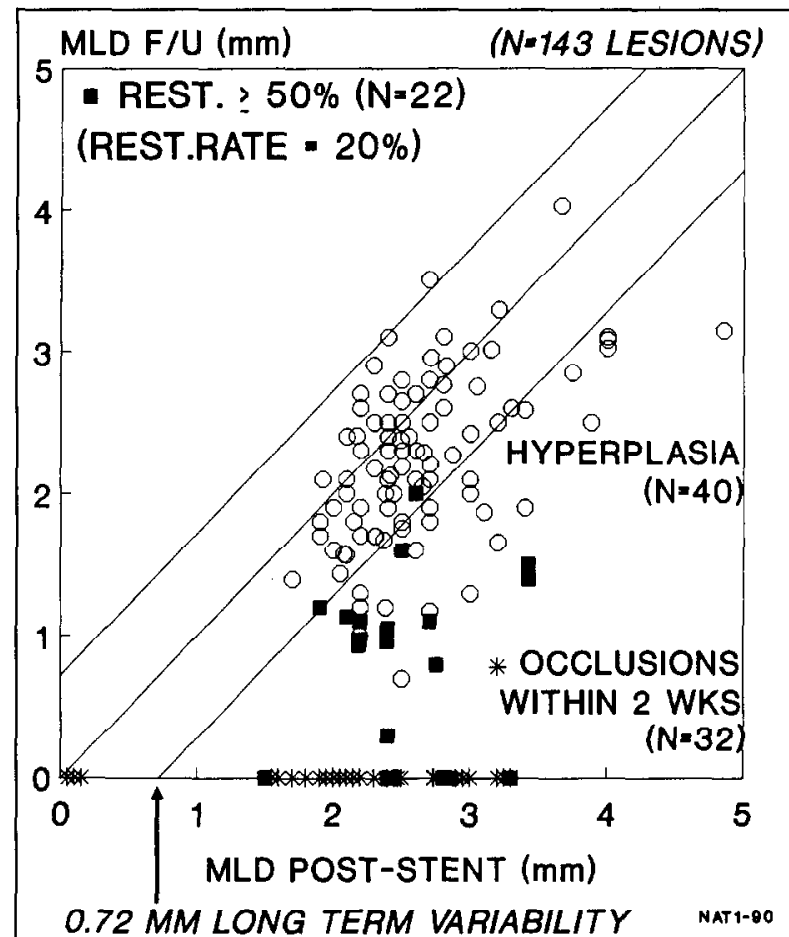

MLD F/U (mm)

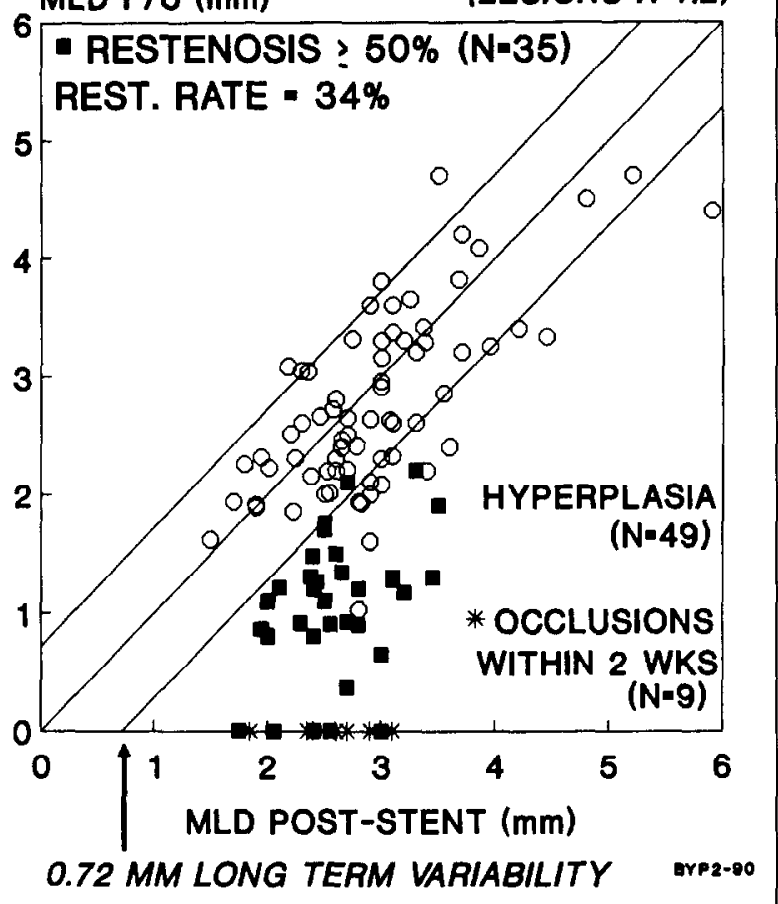

FIOURE 3. Change in the minimal hminal diameter (MLD) for individual lections in native vecsels (top) and in bypass grafts (bottom) between stent implentation and angiographic followup (F/U). The dinmeter of each segment immedifely after im* plantation is plotted against the diameter at follow-up. The ines en each side of the identity line (diagonal) represent the "mits of long-term varish"ity of repeat measurements (a chenge of $\geq 0.72 \mathrm{~mm}$ (arrow]). Al symbols below the righthand ine represent stents with involvement of anglographic detectable hyperplesia. Filled squares represent lesions with follow-ip dismeter stenosis $\geq 50 \%$. Occhusions are located along the $x$ axis, and those that occurred within the first 2 weeks are marked by an asterisk. RIST, = restenosis. duced immediately after stenting in bypass grafts from $60 \pm 1$ to $23 \pm 1 \%$, but increased at late follow-up to 43 \pm 3 and $38 \pm 3 \%$ with and without the early occlusions, respectively ( $p<0.0001$ versus the poststent result). Similar changes were observed in native vessels.

In the overall group, the incidence of early in-hospital occlusion was $15 \%$ in patients and $13 \%$ in lesion. In bypass grafts, early occlusions were documented in $7 \%$ of lesions ( $8 \%$ of patients) versus $18 \%$ of lesions ( $19 \%$ of patients) in native vessels (in lesions, $p=0.005$; in patients, $p=0.016$ ). Three of these native vessel occlusions occurred during the procedure and could not be recanalized. The remaining occlusions presented clinically as acute ischemic syndromes after a successful stenting procedure. Early occlusions were less frequent in group $2(12 \%)$ than in group $1(20 \%)$ patients but not statistically significant. Restenosis in the overall group according to criteria 1 and 2 was $42 \%$ and $27 \%$, respectively (Table III). Restenosis according to either definition was significantly higher in bypass grafts (criterion $1,54 \%$; criterion $2,39 \%$ ) than in native vessels (34 and $18 \%$, respectively) (criterion $1, \mathrm{p}=0.016$; criterion 2 , $p=0.001$ ). Although the restenosis rates by either criterion were higher in group 2 than group 1, these differences were not statistically significant.

The overall mortality during the study period was $9 \%(\mathrm{n}=9)$ for bypass grafts and $6.6 \%(\mathrm{n}=11)$ for native vessels ( 8 and $6 \%$ at 1 year, respectively). The 1 year mortality rate in group 1 and 2 patients was 7.6 and $7.5 \%$, respectively. In patients who underwent bypass surgery, 4 deaths occurred during the initial hospitalization ( 2 intracerebral hematomas related to the anticoagulation and 2 myocardial infarctions due to stent occlusion). Two of the 5 late deaths were sudden (at 2 and 18 months), 2 were unrelated to the stent (chronic heart failure, renal failure), and the other death occurred after bypass surgery. In the stented native vessel group, 7 of the 11 deaths occurred in the hospital. These were due to myocardial infarctions resulting from stent occlusion, with the exception of $1 \mathrm{pa}$ tient with intracerebral bleeding and 1 in cardiogenic shock who underwent stent implantation 24 hours after a myocardial infarction. Two of the 4 late deaths were sudden (at 1.5 and 19 months), 1 was noncardiac (pneumonia) and the other occurred after bypass surgery. The actuarial event-free survival (freedom from death, myocardial infarction, bypass surgery or angioplasty) for native artery patients was $46 \%$ at 40 months and for bypass graft patients $37 \%$ at 20 months (Figure 4).

\section{DISCuSSION}

The coronary Wallstent was initially introduced as an endovascular device to prevent the late restenosis process that limits percutaneous transluminal coronary angioplasty. The indications for and management of patients implanted with this particular prosthesis have evolved as experience and knowledge have increased. In this study, an attempt has been made to separate $2 \mathrm{im}$ portant factors in the late outcome of patients with stent implantations. The first division, according to date of implantation, provides the clearest picture of the 
changes in stent applications based on the early experience. Investigators originally believed that the stent could be safely implanted in native vessels and that the benefit of stents would be most apparent in lesions that had already restenosed on at least 1 occasion. However, a high in-hospital occlusion rate was noted, particularly in patients with unstable syndromes, evolving myocardial infarction or angiographic evidence of thrombus.
These occlusions, often with disastrous clinical sequelae, convinced most of the investigators that native vessels in general and particularly in the left anterior descending artery (due to the large territory at risk) should only be implanted in bailout situations. Group 2 mainly consisted of patients with bypass grafts who underwent stent implantation for primary lesions and those in whom native vessels were implanted as part of a bailout strategy

\begin{tabular}{|lccccc|}
\hline \multicolumn{4}{|c|}{ TABLE III Late Angiographic Follow-Up: Restenosis Within and Immediately Adjacent to the Stent } & \\
\hline & Total & Group 1 & Group 2 & Native Vessels & Bypass Grafts \\
\hline Narrowings/patients & $214 / 176$ & $85 / 75$ & $129 / 101$ & $111 / 104$ & $103 / 74$ \\
0.72 mm criterion & $75 / 61$ & $25 / 21$ & $50 / 40$ & $35 / 30$ & $40 / 31$ \\
Within stent & $14 / 14$ & $5 / 5$ & $9 / 9$ & $5 / 5$ & $9 / 9$ \\
Adjacent to stent & $89 / 75$ & $30 / 26$ & $59 / 49$ & $40 / 35$ & $49 / 40$ \\
Total & $(42 \% / 43 \%)$ & $(37 \% / 35 \%)$ & $(46 \% / 49 \%)$ & $(36 \% / 34 \%)$ & $(48 \% / 54 \%)$ \\
50\% diameter stenosis criterion & $51 / 42$ & $17 / 15$ & $34 / 27$ & $21 / 18$ & $30 / 24$ \\
Within stent & $6 / 6$ & $1 / 1$ & $5 / 5$ & $1 / 1$ & $5 / 5$ \\
Adjacent to stent & $57 / 48$ & $18 / 16$ & $39 / 32$ & $22 / 19$ & $35 / 29$ \\
Total & $(27 \% / 27 \%)$ & $(22 \% / 21 \%)$ & $(30 \% / 32 \%)$ & $(20 \% / 18 \%)$ & $(34 \% / 39 \%)$ \\
\hline
\end{tabular}

FIGURE 4. Chrical follow-up in native vessels up to 40 months (top) and bypass grafts up to 20 months (bottom) according to ectuarial event-free survival. The y axis represents the proportion of patients without a clinical event, and time after impian. tation (in months) is clong the $x$ axis. The curves (from uppor to lower) represent freedom from death (DTH) slone; death phus myocardlal infaretion (MII); death, myocardidd Infarction phes bypass surgery (BYP); and dasth, myocardial infarction, bypass surgery phus engloplasty or atherectomy (PT).

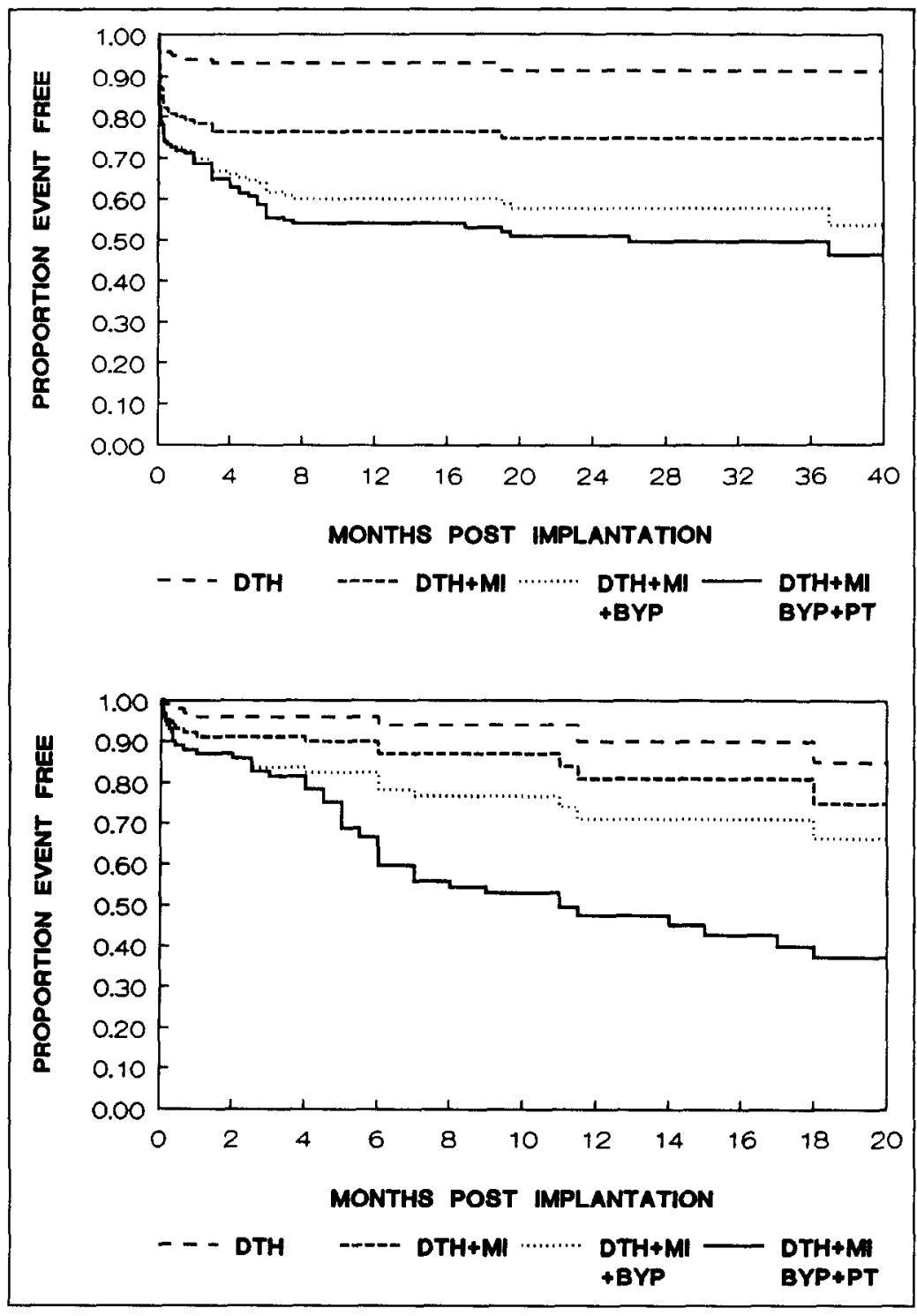


after complicated angioplasty. Bypass grafts, in particular, were selected for stent implantations owing to an extremely high rate of restenosis after angioplasty alone, and the larger diameter of these grafts seemed less likely to thrombose than smaller caliber native arterial vessels. ${ }^{11-14}$ Bypass lesions, which composed most of the lesions implanted in group 2, were generally more complex than group 1 lesions owing to the advanced age and diffuse nature of the disease in the bypass grafts. As a result, more stents per lesion (1.4 versus 1.1 in native vessels) were required to cover these lesions. Therefore, the significantly lower rate of in-hospital occlusion in patients with bypass grafts versus patients with native vessels (8 versus 19\%) and the trend in group 2 versus group 1 (12 versus 20\%) are indicative of several possible factors including improvements in anticoagulation regimens, operator experience or larger caliber vessels despite more complex case selection. Higher restenosis rates by both criteria were demonstrated in bypass grafts and in group 2 patients. There are 2 possible explanations for this increase. First, bypass grafts, which are overrepresented in group 2, are known to have higher restenosis rates than native vessels. ${ }^{11-13} \mathrm{Sec}-$ ond, higher restenosis rates may be the "price" for lower occlusion rates. Organization of thrombus at the site of intimal damage may be an important cause of late restenosis after stenting. Although it is often difficult to histologically differentiate thrombus organization from intimal hyperplasia, we have observed an extremely disorganized pattern of intimal thickening in the stented segments of several bypass grafts that have been surgically retrieved or obtained by atherectomy 1 to 5 months after stent implantation..$^{15}$ By diminishing the formation of early occlusive thrombus with more effective anticoagulation, the residual nonoccluding thrombus could form the substrate for late restenosis. Although the second group had a higher proportion of bailout cases, a previous study from our group did not identify increased relative risk for restenosis from bailout cases compared with primary or restenosed lesions. ${ }^{16}$

The high incidence of late adverse clinical events in patients with stents is a cause for concern. A mortality rate of $9 \%$ in bypass grafts and $6.6 \%$ in native vessels is higher than in reported angioplasty studies. ${ }^{17-19}$ However, it must be stressed that a large number of stents in native vessels were implanted for abrupt closure after angioplasty, which dramatically increases the risk of the procedure. ${ }^{20}$ Actuarial event-free survival was $37 \%$ at 20 months in patients who had had bypass surgery and $46 \%$ at 40 months in native vessels. In the bypass group, about $30 \%$ of the adverse events were unrelated to the stented lesion and were due to worsening of a different lesion or to development of new lesions. In the native vessel group, $12 \%$ of the adverse events were unrelated to the stented lesion. In addition, 9 of the 30 bypass operations in patients with stented native vessels were performed as part of a protocol for patients stented for the bailout indication. ${ }^{20}$ Although there are no comparable series of patients with stented native vessels in the literature because of the unique set of indications in our study, 3 recent reports have been published on late clinical follow-up after angioplasty in bypass grafts. The Thoraxcenter reported that only $41 \%$ of patients were alive and event-free (myocardial infarction, repeat bypass surgery, repeat angioplasty) at a median follow-up of 2.1 years. $^{21} \mathrm{~A}$ review of the overall Dutch experience also showed limited late beneficial results with a 2- and 5 -year event-free survival of 52 and $26 \%$, respectively, in 454 patients who underwent bypass surgery. ${ }^{22} \mathrm{Webb}$ et al ${ }^{11}$ described a $71 \%$ freedom from death, infarction and surgery at 5 years in bypass patients who underwent angioplasty at their institution, but did not include the $27 \%$ incidence of second angioplasty procedures also required in their patient group. However, our study was not a randomized trial designed to compare stenting with angioplasty, but rather an observational study with a first-generation coronary stent. Nevertheless, all of these late follow-up studies of nonoperative coronary revascularization clearly show that these are palliative procedures and not long-term solutions to the underlying problems of progression of underlying coronary disease and iatrogenically induced restenosis.

Several important points emerge from this study. Although in-hospital occlusion rates improved in the later experience, thrombosis of the Wallstent continues to limit its use. Restenosis rates with the $50 \%$ diameter stenosis criterion do not seem to be significantly improved when compared with historical results after angioplasty, although definitive statements must await randomized trials. Bypass grafts, in particular, had a high incidence of late restenosis, although early occlusion occurred less significantly than in native vessels. There is insufficient evidence at this time to implant a coronary stent outside of a randomized trial with the following exceptions: (1) bailout for abrupt occlusion; (2) suboptimal (inadequate dilatation) results after angioplasty; and (3) bypass grafts at high risk (e.g., friable lesions) for distal embolization with angioplasty that may benefit from the scaffolding property of the Wallstent.

Acknowledgment: We gratefully acknowledge the assistance of Christel van Hooij in the preparation of the manuscript, and Edward Murphy, MD, for critical comments.

\section{APPENDIX}

Participating Centers and Collaborators: Catheterization Laboratory for Clinical and Experimental Image Processing, Thoraxcenter, Rolterdam, the Netherlands: B.H. Strauss, MD, K.J. Beatt, MB, BS, M. v.d. Brand, MD, P.J. de Feyter, MD, H. Suryapranata, MD, I.K. de Scheerder, MD, J.R.T.C. Roelandt, MD, P.W. Serruys, MD; Department of Cardiology, Hopital Cardiologique, Lille, France: M.E. Bertrand; Department of Invasive Cardiology, The Royal Brompton and National Heart Institute, London, United Kingdom: A.F. Rickards, MD, U. Sigwart, MD; Department of Clinical and Experimental Cardiology, CHRU Rangeuil, Toulouse, France: J.P. Bounhoure, MD, A. Courtault, MD, F. Joffre, MD, J. Puel, MD, H. Rousseau, 
MD; Division of Cardiology, Department of Medicine, CHUV, Lausanne, Switzerland: J.-J. Goy, MD, J-C Stauffer, MD, U. Kaufmann, MD, L. Kappenberger, MD, P. Urban, MD; Cardiology Center, University Hospital, Geneva, Switzerland: B. Meier, P. Urban.

\section{REFERENCES}

1. Sigwart U, Puel J, Mirkovitch V, Joffre F, Kappenberger L. Intravascular stents to prevent occlusion and restenosis after transluminal angioplasty. $N$ Engl $J$ Med 1987;316:701-706.

2. Serruys PW, Strauss BH, Beatt KJ, Bertrand ME, Puel J, Rickards AF, Meie B, Kappenberger L, Goy JJ, Vogt P, Sigwart U. Quantitative follow-up after placement of a self-expanding coronary stent. $N$ Engl J Med 1991;324:13-17. 3. Strauss BH, Juilliere Y, Rensing BJ, Reiber JHC, Serruys PW. Edge detection versus densitometry for assessing coronary stenting quantitatively. $\mathrm{Am} J \mathrm{Cardio}$ 1991;67:484-490.

4. Serruys PW, Juilliere Y, Bertrand ME, Puel J, Rickards AF, Sigwart U. Additional improvement of stenosis geometry in human coronary arteries by stenting after balloon dilatation. Am J Cardiol 1988;61:71G-76G

5. Puel J, Juilliere Y, Bertrand ME, Rickards AF, Sigwart U, Serruys PW. Early and late assessment of stenosis geometry after coronary arterial stenting. $\mathrm{Am} \mathrm{J}$ Curdiol 1988:61:546-553.

6. Reiber JHC, Serruys PW, Kooijman CJ, Wijns W, Slager CJ, Gerbrands JJ, Schuurbiers JCH, den Boer A, Hugenholtz PG. Assessment of short-, mediumand long-term variations in arterial dimensions from computer-assisted quantitation of coronary cineangiograms. Circulation 1985;71:280-288.

7. Serruys PW, Luijten HE, Beatt KJ, Geuskens R, de Feyter PJ, van den Brand M, Reiber JHC, ten Katen HJ, van Es GA, Hugenholtz PG. Incidence of restennsis after successful coronary angioplasty: a time-related phenomenon. Circulation 1988:77:361-371

8. Beatt KJ, Luijten HE, de Feyter PJ, van den Brand M, Reiber JHC, Serruys PW. Change in diameter of coronary artery segments adjacent to stenosis after percutaneous transluminal coronary angioplasty: failure of percent diameter stenosis measurement to reflect morphologic changes induced by balloon dilation. $J$ Am Coll Cardiol 1988;12:315-323.

9. Serruys PW, Rutsch W, Heyndrickx GR, Danchin N, Mast EG, Wijns W Rensing BJ, Vos J, Stibbe J. Prevention of restenosis after percutaneous transluminal coronary angioplasty with thromboxane $A 2$ reccptor blockadc. $A$ randomized, double-blind, placebo controlled trial. Circulation 1991;84:1568-1580. 10. Kaplan EL, Meier P. Nonparametric estimation from incomplete observations. J Am Stat Assoc 1958;53:457-481.
11. Webb JG, Myler RK, Shaw RE, Anwar A, Mayo JR, Murphy MC, Cumberland DC, Stertzer SH. Coronary angioplasty after coronary bypass surgery: initial results and late outcome in 422 patients. $J$ Am Coll Cardiol 1990;16:812-820. 12. Douglas JS, Gruentzig AR, King SB III, Hollman J, Ischinger T, Meier B, Craver JM, Jones EL, Waller JL, Bone DK, Guyton R. Percutaneous transluminal coronary angioplasty in patients with prior coronary bypass surgery. $J \mathrm{Am} \mathrm{Coll}$ Cardiol 1983;2:745-754

13. Block PC, Cowley MJ, Kaltenbach M, Kent KM, Simpson J. Percutaneous angioplasty of stenoses of bypass grafts or of bypass graft anastomosis sites. $A m J$ Cardiol 1984:53:666-668.

14. Bucx JJJ, de Scheerder I, Beatt K, van der Brand M, Suryapranata H, de Feyter P, Serruys PW. The importance of adequate anticoagulation to prevent Early thrombosis following stenting of stenosed venous bypass grafts. Am Heart $J$ 1991;121:1389-1396.

15. Serruys PW, Strauss BH, van Beusekom HM, van der Giessen WJ. Stenting of coronary arteries. Has a modern Pandora's Box been opencd? J Am Coll Cardiol 1991;17:143B-154B.

16. Strauss BH, Serruys PW, de Scheerder IK, Tijssen JGP, Bertrand MB, Puel J. Meier B, Kaufmann U, Stauffer JC, Rickards AF, Sigwart I. . A relative risk analysis of the angiographic predictors of restenosis in the coronary Wallstent ${ }^{\oplus}$. Circulation 1991;84:1636-1643.

17. Kent KM, Bentivoglio LG, Block PC, Bourassa MG, Cowley MJ, Dorros G, Detre KM, Gosselin AJ, Gruentzig AR, Kelsey SF, Mock MB, Mullin SM, Passamani ER, Myler RK, Simpson J, Stertzer SH, van Raden MJ, Williams DO. Long-term efficacy of percutaneous transluminal coronary angioplasty (PTCA): report from the National Heart, Lung, and Blood Institute PTCA Registry. Am J Cardiol 1984;53:27C-31C

18. Gruentzig AR, King SB III, Schlumpf M, Siegenthaler W. Long-term follow-up after percutancous transluminal coronary angioplasty. The early Zurich experience. N Engl J Med 1987;316:1127-1132.

19. Detre K, Holubkov R, Kelsey S, Bourassa M, Williams D, Holmes D Jr, Dorros G, Faxon D. Myler R, Kent K, Cowley M, Cannon R, Robertson T. Oneyear follow-up results of the 1985-1986 National Heart, Lung, and Blood Institute's percutaneous transluminal coronary angioplasty registry. Circulation 1989;80:421-428.

20. de Feyter PJ, de Scheerder I, van den Brand M, Laarman G, Suryapranata $\mathrm{H}$, Serruys PW. Emergency stenting for refractory acute coronary artery occlusion during coronary angioplasty. Am J Cardiol 1990;66:1147-1150.

21. Meester BJ, Samson M, Suryapranata $H$, Bonsel $G$, van den Brand $M$, de Feyter PJ, Serruys PW. Long-term follow-up after attempted angioplasty of saphenous vein grafts: the Thoraxcenter experience 1981-1988. Eur Heart J 1991;12:648-653.

22. Plokker HWT, Meester BH, Serruys PW. The Dutch experience in percutaneous transluminal angioplasty of narrowed saphenous veins used for aortocoronary arterial bypass. Am J Cardiol 1991;67:361-366. 